\title{
A EXTENSÃO DA PLATAFORMA CONTINENTAL BRASILEIRA ALÉM DAS 200 MILHAS MARÍTIMAS: OPORTUNIDADES E DESAFIOS
}

\section{Marcelo Fernando Quiroga Obregón ${ }^{1}$ Francisco Lima Guaitolini ${ }^{2}$}

O presente trabalho tem como objetivo investigar, a partir da Convenção das Nações Unidas sobre o Direito do Mar, o regime jurídico da plataforma continental e a sua possibilidade de extensão além das 200 milhas marítimas, prevista no artigo 76, abordando o funcionamento da Comissão de Limites da Plataforma Continental, bem como responder questões atinentes aos seus impactos econômicos na exploração de petróleo, gás natural e outros recursos minerais do leito e subsolo oceânicos sob soberania do Estado brasileiro, que compõem a Amazônia Azul. De igual modo, prevê-se sob a ótica do case brasileiro dificuldades quando a aplicação prática do artigo 82 da Convenção for submetida à prova dos fatos, o que realça a concepção de que exploração da plataforma continental estendida gerará uma série de oportunidades e desafios ao país.

Palavras-chave: Artigo 76. Amazônia Azul. Convenção das Nações Unidas sobre o Direito do Mar. Comissão de Limites da Plataforma Continental. Expansão da Plataforma Continental.

\section{INTRODUÇÃO}

A Convenção das Nações Unidas sobre o Direito do Mar, assinada em 10 de dezembro de 1982, em Montego Bay, trouxe uma série de inovações que representavam os anseios da comunidade internacional. Entre estas, é possível destacar o regime jurídico da plataforma continental, que é um dos, se não o mais, complexo dos espaços marítimos definidos pelo diploma.

\footnotetext{
${ }^{1}$ Doutor em Direitos e Garantias Fundamentais pela Faculdade de Direito de Vitória - FDV. Coordenador Acadêmico do curso de especialização em Direito Marítimo e Portuário da Faculdade de Direito de Vitória - FDV. Professor de Direito Internacional e Direito Marítimo e Portuário nos cursos de graduação e pós-graduação da Faculdade de Direito de Vitória - FDV - Brasil. E-mail: mfqobregon@yahoo.com.br

2 Graduando em Direito pela Faculdade de Direito de Vitória - FDV - Brasil. E-mail: franciscolima.g@hotmail.com
} 
Segundo o artigo 76 da Convenção, é previsto ao Estado costeiro o direito de estender o limite exterior de sua plataforma continental além das 200 milhas marítimas caso preenchidos alguns requisitos. Nesse sentido, diversos países, entre os quais o Brasil, tiveram suas intenções amparadas pela Convenção.

O Estado brasileiro reivindica frente às Nações Unidas o reconhecimento do novo limite exterior de sua plataforma continental, o que amplia a área do leito e subsolo marinho sob jurisdição nacional e torna ainda maior a Amazônia Azul.

No entanto, a exploração da plataforma continental estendida deve atender a uma série de determinações impostas pelo artigo 82 da Convenção, o que vem gerando uma profunda insegurança jurídica à comunidade internacional. Isso decorre das incertezas no que se refere a interpretação e aplicação do dispositivo.

A temática é extramamente hodierna e carece de estudos na área do Direito. Além do mais, demonstra-se relevante em razão de suas indefinições, que prometem impactar substancialmente as políticas adotadas pelos Estados costeiros para exploração dos recursos do leito e subsolo marinhos num futuro próximo.

Em vista disso, explanar-se-á no primeiro momento um breve histórico da plataforma continental e os seus aspectos jurídicos, nos termos da Convenção das Nações Unidas sobre o Direito do Mar. Deste modo, será possível compreender de forma ampla o contexto da plataforma continental desde sua primeira manifestação até o presente.

No segundo momento, o estudo remeter-se-á ao processo de extensão da plataforma continental além das 200 milhas marítimas sob a ótica do case brasileiro, que se encontra em constante evolução. A análise pormenorizada do caso concreto permitirá esclarecer as particularidades e desdobramentos do pleito brasileiro frente à ONU.

Por fim, no último capítulo será realizada uma abordagem à respeito do regime jurídico de exploração da plataforma continental estendida a partir do artigo 82 da CNUDM e das medidas que o Estado brasileiro vem tomando. Nessa perspectiva, será possível visualizar as oportunidades e desafios que o país deve enfrentar nos próximos anos ao explorar a plataforma continental além das 200 milhas marítimas. 


\section{PLATAFORMA CONTINENTAL: ASPECTOS HISTÓRICOS E JURÍDICOS}

Os direitos de soberania e jurisdição sobre os espaços marítimos encontram-se regulamentados, em âmbito internacional, pelo direito do mar, sendo este um ramo de extrema importância do direito internacional público, visto que, essencialmente, delimita a natureza e a extensão do domínio marítimo e a limitação da jurisdição de cada Estado em conflitos que versem sobre o direito marítimo (MARTINS, 2013, p. 3).

Conforme define Eliane M. Octaviano Martins (2013, p. 10)

Considera-se o direito do mar o conjunto das normas legais que regulam a utilização do mar, atuando na prevenção e solução de conflitos que delimitam as fronteiras e a extensão do domínio marítimo, bem como os respectivos direitos de soberania e jurisdição. Restringe-se às relações internacionais entre Estados soberanos sobre jurisdição e competência atribuídas a cada um deles no que se refere aos territórios marítimos e age, consquenemente, na prevenção e solução de conflitos entre os Estados.

Portanto, seguindo as necessidades de regulamentação dos espaços marítimos, seja por questões econômicas, seja por questões políticas, são, então, assim reconhecidos pela Convenção das Nações Unidas Sobre o Direito do Mar as Águas Interiores, o Mar Territorial, a Zona Contígua, a Zona Econômica Exclusiva, a Plataforma Continental, ${ }^{1}$ o Mar Alto e a Área. Dentre estes, no que diz respeito a Plataforma Continental, é acolhida sua primeira manifestação em âmbito internacional no ano de 1945, a partir do pronunciamento do Presidente dos Estados Unidos - Harry S. Truman - o qual estabeleceu unilateralmente a extensão da plataforma continental norte-americana, e foi sucedido por outros países, inclusive o Brasil (MENEZES, 2015, p. 136), através do Decreto ${ }^{\circ}$ 28.840 , de 8 de novembro de 1950 .

Carla Adriana C. Gibertoni esclarece que (2014, p. 40)

O instituto da plataforma continental penetrou de modo amplo no mundo jurídico, e sobretudo no Direito Internacional Público, através do costume internacional, que, após diversos atos unilaterais dos Estados, criou uma prática uniforme, sem quaisquer protestos.

Entretanto, o movimento de unilateralidade era completamente incompatível com o contexto do pós-Segunda Guerra Mundial, uma vez que ensejava ao uso da força acaso não houvesse consenso entre as nações acerca da delimitação e do regime jurídico da plataforma continental. 
Em vista disso, a comunidade internacional, sob a supervisão da $\mathrm{ONU}$, lançou mão dos tratados internacionais para normatizar uma matéria que durante séculos teve como principal fonte o direito costumeiro. Sidney Guerra $(2015$, p. 87$)$ explica que

\begin{abstract}
Diferentemente do que acontecia no passado, os tratados internacionais são considerados a principal fonte do Direito Internacional. Ao ser concebida uma norma escrita no plano internacional (tratado), evidencia-se maior segurança jurídica no âmbito das relações internacionais, principalmente se se levar em conta que no passado a principal fonte de Direito Internacional Público era o costume. A sociedade internacional se apresentava de forma estática e hodiernamente se apresenta de forma dinâmica.
\end{abstract}

Nesse sentido, após uma série de reinvidicações da sociedade internacional, foi com a celebração da Convenção de Genebra (1958) que a plataforma continental consolidou-se como espaço geográfico-marítimo e teve o seu regime jurídico definido (GOUVEIA, 2004, p. 163). A Convenção adotou como critério para a definição da plataforma continental a profundidade — até duzentos metros — e a explorabilidade — até onde fosse possível.

Apesar de a Convenção de Genebra ter regulado pela primeira vez a plataforma continental em âmbito internacional, não é difícil perceber o quão desequilibrados foram os critérios para delimitação desta, uma vez que, por um lado, prejudicavam os países geomorfologicamente desfavorecidos, por outro, beneficiavam os países desenvolvidos que detinham tecnologias de exploração capazes de alcançar os recursos do leito e subsolo marinho.

Posteriormente à Convenção de 1958, surge como grande marco regulatório a Convenção das Nações Unidas sobre o Direito do Mar (CNUDM), votada na III Conferência das Nações Unidas sobre o Direito do Mar, em Montego Bay (1982). Nas palavras de Eliane M. Octaviano Martins (2013, p. 11), “a evolução do processo geral de codificação do direito do mar encontra seu ápice na CNUDM, que efetivamente se consagra como a Lei do mar (Law of the sea)".

A Convenção conta até o momento com a adesão de mais de 150 países e é composta por 320 artigos — distribuídos em 17 partes e 9 anexos — sendo assim o principal diploma normativo que regula o direito do mar. Destarte, Wagner Menezes (2015, p. 20) elucida que

A normatização do mar só foi possível por conta da liderança e perseverança da Organização das Nações Unidas (ONU) e das conferências que promoveu até a Convenção das Nações Unidas sobre o Direito do Mar, marco jurídico complexo e avançado sobre a percepção de utilização dos espaços oceânicos como res communes da sociedade internacional. 
Nesta ocasião, as caracterísiticas, conceito e abrangência da plataforma continental foram amplamente debatidos e lhe teve dedicada a Parte VI desta Convenção, que comprende os artigos 76 ao 85. Ademais, sofreu alterações significativas no que se refere à Convenção de Genebra, a começar pela sua definição que adotou novos critérios, sendo estes

[...] um critério de plataforma no sentido geológico - até a borda exterior da margem continental, com o objetivo de preservar os direitos adquiridos pelo regime anterior - e por um critério de extensão de duzentas milhas desde as linhas de base, tratando de satisfazer os Estados que careciam de plataforma no sentido destacado ou que tinham escassas dimensões (MENEZES, 2015, p. 137).

O caráter equitativo da Convenção é averiguado a partir da garantia aos Estados geomorfologicamente desfavorecidos de uma plataforma em sentido jurídico, até as 200 milhas marítimas (GUEDES, 1998, p. 189).

No que tange à definição da plataforma continental, é possível descrevê-la como um prolongamento natural do espaço terrestre que adentra ao mar e culmina no momento em que a elevação continental se aprofunda até os abismos oceânicos (ZANELLA, 2013, p. 277). Ocorre que, para não deixar margens à diferentes interpretações, a CNUDM teve o zelo de datalhar o conceito de plataforma continental em um de seus artigos.

De acordo com o artigo $76, \S 1^{\circ}$ da Convenção, a plataforma continental de um Estado costeiro compreende o leito e o subsolo das áreas submarinas que se estendem além do seu mar territorial, em toda a extensão do prolongamento natural do seu território terrestre, até ao bordo exterior da margem continental ou até uma distância de 200 milhas marítimas das linhas de base a partir das quais se mede a largura do mar territorial, nos casos em que o bordo exterior da margem continental não atinja essa distância. Consequentemente, não estão cobertos pelo regime jurídico da plataforma continental os grandes fundos oceânicos — inclusive as suas cristas oceânicas — nem o seu subsolo. Ainda é previsto pela CNUDM a possibilidade de se definir o limite exterior da plataforma continental além das 200 milhas marítimas, ${ }^{2}$ sendo essa uma das maiores inovações abarcadas pela Convenção, o que será abordado exclusivamente à frente.

Outro fator a ser considerado para a definição da plataforma continental é a existência de Estados com costas adjacentes ou situadas frente a frente. Na ocorrência desta hipótese

[...] os Estados envolvidos deverão procurar por acordo, ainda que provisório, uma solução equitativa. Na falta ou impossibilidade disso, o limite externo das 
respectivas plataformas deverá ser fixado por meios pacíficos, previstos nos arts. 279 e segs. (GUEDES, 1998, p. 190).

Uma vez determinados os limites da plataforma continental entre os Estados, as cartas ou listas de coordenadas geográficas devem ser depositadas junto ao Secretário-Geral das Nações Unidas bem como ter a devida publicidade.

No que se refere aos direitos sobre a plataforma continental, o Estado costeiro exerce direitos de soberania para efeitos de exploração e aproveitamento dos seus recursos naturais. São estes exlcusivos, no sentido de que, se o Estado não explorar ou aproveitar os recursos naturais da plataforma continental, ninguém poderá empreender estas atividades sem o expresso consentimento desse Estado.

Sob este ângulo, Maria Augusta Paim (2014, p. 337) explica que "antes de mais nada, deve-se esclarecer que, contrariamente à crença popular, o Brasil não exerce soberania sobre todas as zonas marítimas adjacentes à sua costa, a soberania é exercida apenas sobre o mar territorial e as águas marítimas interiores".

Embora sejam assegurados uma série de direitos ao Estado costeiro no que diz respeito à plataforma continental, estes não afetam o regime jurídico das águas sobrejacentes e do espaço aéreo. Logo, o exercício dos direitos do Estado costeiro sobre a plataforma não deve afetar a navegação ou outros direitos e liberdades dos demais Estados.

Além disso, o Estado costeiro possui "[...] o direito exclusivo de autorizar e regulamentar as perfurações na plataforma continental, quaisquer que sejam os fins, de construir e instalar estruturas (nos termos do artigo 60 da Convenção) e de escavar túneis em seu subsolo" (MENEZES, 201, p. 139). Em relação aos cabos e dutos submarinos, o Estado costeiro não pode impedir a colocação ou a manutenção dos mesmos, mas deve estabelecer as condições para tanto.

Assim, destaca-se a enorme importância da plataforma continental, visto que esta amplia - e muito - as possibilidades de exploração de recursos naturais pelos Estados, que vão desde recursos minerais e outros recursos não-vivos do leito e subsolo do mar, até organismos vivos pertecentes a espécies sedentárias, que no período da captura estão imóveis no leito do mar e no subsolo ou só podem mover-se em constante contato físicos com esses. 


\subsection{A EXTENSÃO DA PLATAFORMA CONTINENTAL ALÉM DAS 200 MILHAS MARÍTIMAS}

Uma das maiores inovações apresentadas pela CNUDM é a possibilidade de os Estados costeiros estenderem suas plataformas continentais além das 200 milhas marítimas. Nesse sentido, como disciplina o artigo 76 da Convenção, a plataforma continental destes Estados pode atingir uma distância que não exceda as 350 milhas marítimas da linha de base a partir da qual se mede a largura do mar territorial ou uma distância que não exceda 100 milhas marítimas da isóbata de 2500 metros, que é uma linha que une profundidades de 2500 metros. ${ }^{3}$ Portanto, “[...] o delineamento da PCJ é feito pela utilização integrada dos critérios da margem continental (CNUDM, artigo 76, par. 4) com os critérios de restrição da extensão máxima da PCJ” (GIBERTONI, 2014, p. 46).

A extensão da plataforma continental além das 200 milhas marítimas depende de critérios geológicos, ou seja, que haja de fato um prolongamento natural do talude continental do Estado costeiro. Logo, caso existam elevações submarinas que sejam componentes naturais da margem continental, tais como os seus planaltos, elevações continentais, topes, bancos e esporões, é possível que a plataforma estendida ainda ultrapasse as 350 milhas marítimas.

Segundo Carla Adriana C. Gibertoni (2014, p. 41)

Em síntese, a plataforma continental é um prolongamento natural da massa terrestre de um Estado costeiro. Em alguns casos, ela ultrapassa a distância de 200 milhas da ZEE. Pela Convenção sobre o Direito do Mar, o Estado costeiro pode pleitear a extensão de sua Plataforma até o limite de 350 milhas náuticas, (648 $\mathrm{km}$ ), a partir das linhas de base ou 100 milhas de distância a partir da isóbota de 2500 metros, obsevando-se alguns parâmetros técnicos. O Estado pode optar pelo que mais lhe convier. Isso significa que a plataforma continental pode avançar além de 350 milhas marítimas.

Para que seja reconhecida a plataforma estendida é necessário que o Estado costeiro submeta à Comissão de Limites da Plataforma Continental (CLPC) informações sobre os limites exteriores da sua plataforma continental. A Comissão deverá avaliar e emitir recomendações acerca dos limites da plataforma estabelecidos pelo Estado costeiro, que então, com base nas recomendações, passarão a ser definitivos e obrigatórios. 
Uma vez reconhecida a plataforma estendida, segundo o artigo 82 da CNUDM, o Estado costeiro deverá efetuar, por intermédio da Autoridade Internacional dos Fundos Marinhos (AIFM), pagamentos ou contribuições em espécie relativos ao aproveitamento dos recursos não-vivos da parte da plataforma continental situada para além das 200 milhas marítimas. A AIFM distribuirá os pagamentos ou as contribuições entre os Estados-Partes da Convenção levando em consideração critérios de repartição equitativa, tendo em conta os interesses e necessidades dos Estados em desenvolvimento, e particularmente entre eles, os menos desenvolvidos e sem litoral.

Destarte, esses pagamentos ou contribuições devem iniciar-se a partir do sexto ano de exploração, com a taxa de $1 \%$ sobre toda a produção do sítio, e seguir aumentado em $1 \%$ ao ano até o décimo segundo ano de exploração, momento em que se estabiliza aos 7\% . Ainda assim, caso o Estado costeiro seja um Estado em desenvolvimento e importador substancial de um recurso mineral extraído da sua própria plataforma continental, este fica isento dos pagamentos ou contribuições em relação a esse recurso mineral.

Não restam dúvidas de que o artigo 82 da Convenção de Montego Bay foi a forma encontrada na III Conferência das Nações Unidas sobre o Direito do Mar para resolver o conflito de interesses entre o grupo dos Estados geograficamente desfavorecidos e o grupo dos Estados com plataformas continentais largas ou com extensos litorais. Acontece que a redação do dispositivo acaba por gerar diversas dificuldades no que toca ao âmbito da interpretação e aplicação.

Nesse diapasão, uma série de questionamentos são factíveis, como aduz Almeida Ribeiro (2015, p. 112) para quem

\footnotetext{
Se se tratar de contribuições em espécie, como se efectuará a entrega? Qual o papel da entidade empresarial que eventualmente fará a exploração dos recursos? Quem suporta o transporte de minérios, hidrocarbonetos ou outros produtos, caso a contribuição seja em espécie? Também nos casos de contribuição em espécie, como se determina o seu valor? Será o valor de mercado? Mas, neste caso, de qual mercado? A AIFM não disporá certamente de meios logísticos próprios para recolher contribuições em espécie, nem de logística para movimentar os produtos recebidos. A expressão "sítio" utilizada no n. ${ }^{\circ} 2$ é muito equívoca: caso se trate, por exemplo, de uma jazida de petróleo ou de gás que se estende por várias zonas marítimas, como identificar o "sítio" para aplicação deste dispositivo?
}

Apesar de ainda não existirem casos de aplicação prática do presente artigo, quando ocorrer, são previstas grandes dificuldades, tendo em vista a indeterminação de muitas expressões utilizadas na 
sua letra e a dificuldade de se chegar a uma interpretação declarativa com caráter vinculativo (RIBEIRO, 2015, p. 111).

Logo, o processo de extensão da plataforma continental ainda levanta uma série de questionamentos. No entanto, é pertinente destacar o seu valor no presente, visto que representa uma possibilidade de ampliação dos direitos de soberania para exploração e aproveitamento econômico de recursos vivos e não-vivos pelos Estados costeiros. Além do mais, os recursos naturais tornam-se cada vez mais escassos nos continentes, assim, paralelamente à evolução das tecnologias de exploração em grandes profundezas, tende a crescer exponencialmente o aproveitamento econômico de recursos do leito e subsolo marinho.

\subsection{A COMISSÃO DE LIMITES DA PLATAFORMA CONTINENTAL}

Diante do processo de extensão da plataforma continental além das 200 milhas marítimas, a Comissão de Limites da Plataforma Continental assume papel importante, sendo esta instituída pela CNUDM em seu artigo 76 e delimitada pelo Anexo II.

A Comissão é o órgão responsável por análisar as propostas de extensão da plataforma continental submetidas pelos Estados e lhes prestar recomendações. Assim, os limites da plataforma continental estabelecidos pelo Estado costeiro com base nessas recomendações são definitivos e obrigatórios. Maria Augusta Paim salienta que (2014, p. 327)

\footnotetext{
Apesar de a plataforma continental estendida ser uma declaração unilateral do Estado costeiro, que existe ipso facto e ab initio, é necessário o "endosso" da CLPC. Além das complexidades técnicas dos critérios de delimitação previstos no artigo 76 da CNUDM, o "endosso" da CLPC faz-se necessário porque, além dos limites da plataforma continental, o solo e subsolo oceânico, referentes à Área, e os respectivos recursos, são patrimônio comum da humanidade, de modo que a extensão da plataforma continental a determinado Estado costeiro é, em última análise, proporcional à diminuição da Área.
}

O Estado costeiro que tiver interesse em ampliar sua plataforma continental para além das 200 milhas marítimas deve, nas formas do artigo $4^{\circ}$ do Anexo II da Convenção, apresentar sua proposta 
à Comissão no prazo de dez anos a contar da entrada em vigor da CNUDM em conformidade com o sistema jurídico do referido Estado.

Entretanto, tendo em vista que as diretrizes técnicas e científicas da CLPC para a elaboração da proposta de extensão da plataforma continental (em conformidade com o artigo $76, \S 8^{\circ}$, da Convenção) somente foram adotadas em 13 de maio de 1999, durante a $11^{\text {a }}$ Reunião dos EstadosPartes da CNUDM (2001), decidiu-se que o prazo de dez anos seria contado a partir de 13 de maio de 1999 para os Estados que tivessem ratificado a Convenção antes dessa data.

Ademais, outra questão levantada por alguns Estados costeiros em desenvolvimento foi a dificuldade encontrada para a apresentação das suas propostas de extensão da plataforma continental além das 200 milhas marítimas dentro do prazo de dez anos, em razão de não deterem as tecnologias necessárias para pesquisas e nem recursos para financiá-las.

Nesse sentido, na $18^{\mathrm{a}}$ Reunião dos Estados-Partes da CNUDM (2008), foi acordado que o prazo de dez anos presente no artigo $4^{\circ}$ do Anexo II, seria cumprido apenas com a submissão de informação preliminar ao Secretário-Geral das Nações Unidas, indicando a pretensão de extensão da plataforma continental além das 200 milhas marítimas e descrevendo o status de preparação e de intenção de se fazer uma proposta frente à CLPC.

Com efeito, o governo do Omã manifestou em 2008 não ter a intenção de oferecer uma proposta de extensão da plataforma continental além das 200 milhas marítimas, entretanto deixou reservado o seu direito de, posteriormente, caso decidisse, propor referida extensão com apoio no artigo $76, \S 8^{\circ}$, da CNUDM. Na sequência, em outubro de 2017, o Omã acabou por apresentar sua proposta à CLPC.

No que toca a composição da Comissão, a CNUDM definiu que esta fosse formada por 21 membros, obrigatoriamente peritos em geologia, geofísica ou hidrografia e eleitos pelos Estados-Partes da Convenção entre os seus nacionais, os quais prestarão serviços a título pessoal. A eleição é realizada numa reunião dos Estados-Partes convocada pelo Secretário-Geral das Nações Unidas sendo escolhidos os candidatos que obtiverem a maioria de dois terços dos votos dos representantes dos Estados-Partes presentes e votantes, para um mandato de cinco anos, podendo ser reeleitos. No sentido de assegurar uma representação geográfica equitativa, devem ser eleitos, pelo menos, três membros de cada área do globo terrestre. 
A apreciação das propostas de extensão da plataforma continenal ficam sob responsabilidade de subcomissões compostas por sete membros. Os integrantes da Comissão que forem nacionais do Estado costeiro interessado ou que o tiverem auxiliado prestando-lhe assessoria científica e técnica a respeito da delimitação da plataforma continental, não serão membros da subcomissão que trate do caso, mas terão o direito a participar, na qualidade de membros, nos trabalhos da Comissão relativos ao caso.

Logo que forem elaboradas as recomendações pela subcomissão responsável pela proposta de um Estado costeiro, estas devem ser apresentadas à CLPC para votação. São aprovadas as recomendações que obtiverem maioria de dois terços dos membros presentes e votantes da Comissão. Portanto, é com base nas recomendações já aprovadas que o Estado deve estabelecer o limite exterior da sua plataforma continental. As decisões tomadas pela Comissão não prejudicam assuntos relacionados à delimitação entre Estados com costas adjacentes ou frente a frente.

Por fim, caso o Estado proponente discorde das recomendações adotadas pela Comissão, deverá, em prazo razoável, apresentar uma proposta revista ou uma nova proposta acompanhada de novas pesquisas que deem suporte ao seu pleito.

\section{A AMAZÔNIA AZUL}

Quando se fala em Amazônia, o primeiro dado a se ter em conta é, sem dúvida, ser ela a maior reserva natural do mundo. Situada na América do Sul, a Floresta Amazônica está presente no território de nove nações, sendo uma delas o Brasil, que contém em seu espaço geográfico a maior parcela desta, ou seja, cerca 5 milhões de $\mathrm{km}^{2}$ de floresta que abrangem três das cinco regiões do país. 
Em virtude de possuir a maior biodiversidade do planeta, é incomensurável a importância da Floresta Amazônica, não só para o Brasil, mas para todo o planeta e para as futuras gerações. Desse modo, uma das maiores responsabilidades assumidas pela nação brasileira é a de usufruir dos inúmeros recursos presentes nessa riqueza natural de forma consciente e sustentável.

Acontece que, nas últimas décadas, o Brasil vem descobrindo uma outra imensa riqueza natural — na expressão de Wagner Menezes (2015, p. 148) — cuja área

[...] corresponde, aproximadamente, à metade do território nacional continental, ou a uma nova Amazônia, não verde e continental, mas em pleno mar: uma Amazônia Azul, imensa em suas dimensões e no potencial das riquezas nela depositadas e de fundamental importância estratégica para a defesa e desenvolvimento econômico do Estado brasileiro.

Em razão de possuir uma área equivalente a $53 \%$ do território brasileiro, com biodiversidade e dimensão semelhantes às da Floresta Amazônica, convencionou-se em denominar referida extensão de "Amazônia Azul” a qual, segundo a Marinha (BRASIL, 2017) assim caracteriza-se:

Essa enorme porção de mar guarda imensas reservas de petróleo e de gás, além de outros recursos não vivos (sal, cascalhos, areias fosforitas, crostas cobaltíferas, sulfetos e nódulos polimetálicos, entre outros) que representam importantes fontes de riquezas para o país, além de conter uma grande variedade de organismos marinhos de valor biotecnológico que possuem propriedades com amplas aplicações, principalmente nas áreas de farmácia, de cosméticos, de alimentos e de agricultura.

A Amazônia Azul é composta pelo Mar Territorial, Zona Contígua, Zona Econômica Exclusiva e a Plataforma Continental que circundam todo o litoral brasileiro e suas ilhas oceânicas, e juntos somam uma área de 3,54 milhões de $\mathrm{km}^{2}$. Entretanto, o que permite a Amazônia Azul alcançar a sua enorme dimensão de 4,5 milhões de $\mathrm{km}^{2}$, é a possibilidade de se estender, em alguns trechos, a plataforma continental brasileira além das 200 milhas marítimas em conformidade com o artigo 76, $\S 8^{\circ}$, da CNUDM.

Devido ao Brasil ter ratificado a CNUDM em dezembro de 1988, foi instituído pelo Decreto $\mathrm{n}^{\circ}$ 98.145, de 15 de setembro de 1989, o Plano de Levantamento da Plataforma Continental Brasileira (LEPLAC), com o propósito de estabelecer o limite exterior da plataforma continental brasileira além das 200 milhas marítimas com fundamento na Convenção. 
Sob a coordenação da Comissão Interministerial para Recursos do Mar (CIRM), inciaram-se em junho de 1987 as atividades do LEPLAC, que foram desenvolvidas em conjunto com a Diretoria de Hidrografia e Navegação da Marinha do Brasil (DHN), Petróleo Brasileiro S.A. (PETROBRAS) e a Comunidade Científica Brasileira.

A primeira fase das atividades foi direcionada para a obtenção de dados. Após o seu término, todos os dados coletados pelas equipes de pesquisa tiveram que ser processados com a finalidade de serem submetidos à CLPC, o que de fato aconteceu no ano de 2004, com a apresentação da proposta de extensão do limite exterior da plataforma continental brasileira para além das duzentas milhas marítimas.

\subsection{A PROPOSTA DE LIMITE EXTERIOR DA PLATAFORMA CONTINENTAL BRASILEIRA}

Segundo a Lei Federal n ${ }^{\circ}$ 8.617, de 4 de janeiro de 1993, o limite exterior da plataforma continental brasileira deve ser fixado em conformidade com os critérios estabelecidos no artigo 76 da Convenção de Montego Bay.

Tendo em vista que a CNUDM entrou em vigor internacionalmente, e no Brasil, em 16 de novembro de 1994, e que o prazo para a apresentação da proposta de extensão da plataforma continental era, preliminarmente, de no máximo dez anos após a entrada em vigor da Convenção para o respectivo Estado interessado, o Brasil submeteu, tempestivamente, a sua proposta à CLPC em 17 de maio de 2004.

O Brasil foi o segundo país a submeter a proposta de extensão da plataforma continental nos termos do artigo 76, $\S 8^{\circ}$, da CNUDM, ficando somente atrás da Rússia, que em 2001 apresentou sua pretensão na mesma direção em áreas dos Oceanos Ártico e Pacífico. Isso demonstra o caráter pioneiro do Brasil no cenário mundial, visto que foi uns dos primeiros Estados a realizar a complexa atividade de pesquisa e levantamento de dados pela margem continetal e submetê-los às Nações Unidas.

A proposta brasileira pretende um acréscimo de $960 \mathrm{mil} \mathrm{km}^{2}$ à plataforma continental sob jurisdição do Estado, desta forma alcançando os 4,5 milhões de $\mathrm{km}^{2}$ de Amazônia Azul. De acordo com o sumário executivo submetido pelo Brasil, a área total reivindicada além das 200 milhas marítimas 
se distribui ao longo da costa brasileira, principalmente nas regiões Norte (região do Cone do Amazonas e Cadeia Norte Brasileira), Sudeste (Região da Cadeia Vitória-Trindade e Platô de São Paulo) e Sul (região de Platô de Santa Catarina e Cone do Rio Grande), o equivalente à soma das áreas dos estados de São Paulo, Paraná, Santa Catarina e Rio Grande do Sul.

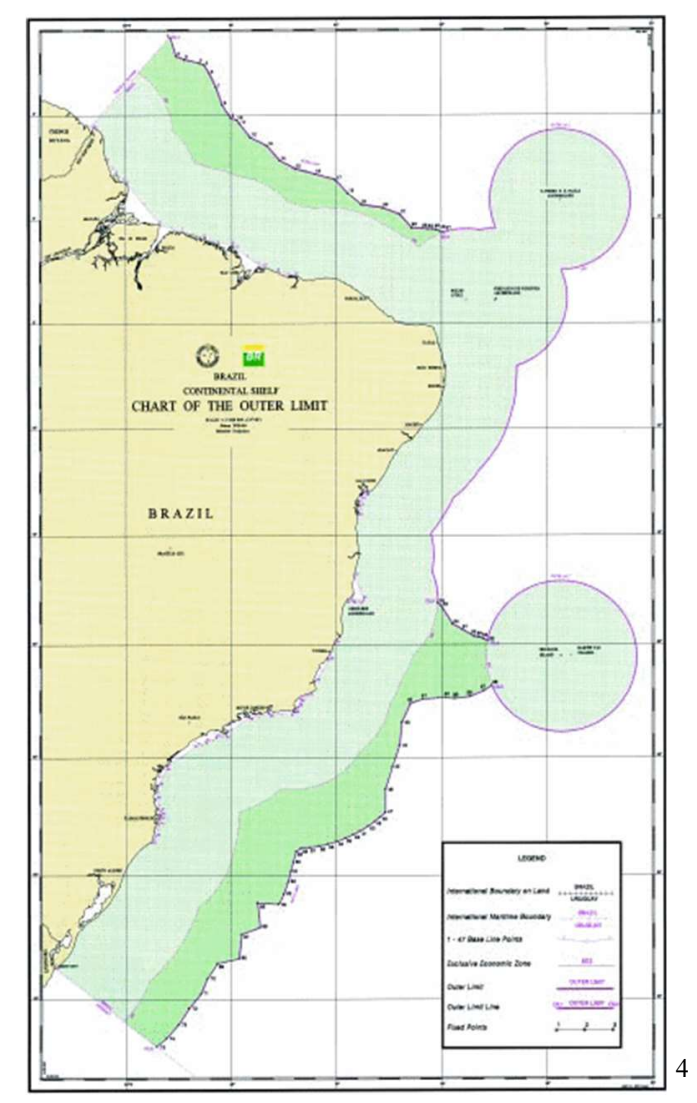

Após ter sido disponibilizado o sumário executivo brasileiro aos Estados-Partes da Convenção, em agosto de 2004 o Estado norte-americano encaminhou às Nações Unidas uma carta na qual manifestou desacordos referentes aos dados coletados pelo Brasil e, além disso, alertou à futura subcomissão responsável pelo pleito brasileiro que o analisasse cuidadosamente. ${ }^{5}$

Ocorre que, somente é previsto pelo Anexo II da Convenção e pelas Regras de Procedimento da CLPC a possibilidade de interferência de um Estado terceiro caso haja disputa entre Estados com costas adjacentes ou situadas frente a frente. Nesse sentido, durante a $14^{\mathrm{a}}$ Reunião da CLPC, foi decidido que a carta norte-americana deveria ser desconsiderada pela Comissão, uma vez que o Brasil possui acordo assinado com ambos os seus Estados vizinhos (Guiana Francesa ao norte e Uruguai ao sul) para definição do limite lateral marítimo e não protagoniza nenhuma disputa marítima. 
Posto isto, com base no artigo 76, $\S 8^{\circ}$, da CNUDM, a Comissão encaminhou ao Estado brasileiro, em abril de 2007, as recomendações em resposta à proposta realizada em 2004. Nessa ocasião, a CLPC não concordou em suas deliberações com cerca de $200 \mathrm{mil} \mathrm{km}^{2}$ dos $960 \mathrm{mil} \mathrm{km}{ }^{2}$ pretendidos pelo Brasil, ${ }^{6}$ visto que não atendiam a todos os requisitos técnicos para seu reconhecimento. Com efeito, o organismo condicionou seu aceite sobre os $760 \mathrm{~km}^{2}$ de área reivindicada pelo Brasil à formalização de uma nova proposta.

\subsection{A PROPOSTA DE EXTENSÃO REVISTA}

É previsto no artigo $8^{\circ}$ do Anexo II da CNUDM, a possibilidade de o Estado costeiro submeter à CLPC uma proposta revista, ou nova proposta, caso este venha a discordar das recomendações feitas pela Comissão. Assim, pelo fato de a pretensão brasileira não ter sido atendida por completo, a CIRM decidiu que fosse oportunamente enviada à CLPC uma proposta revista.

Visando a elaboração do pleito, a CIRM optou por três propostas revistas parciais e fragmentou a margem continental brasileira em três grandes regiões: a Região Sul (Margem Continental Sul), a Região Equatorial (Cone do Amazonas e Cadeia Norte Brasileira) e Região Oriental (Cadeia Vitória Trindade e Platô de Sâo Paulo), as quais juntas somam os 200 mil km² de área não atendidos CLPC. 


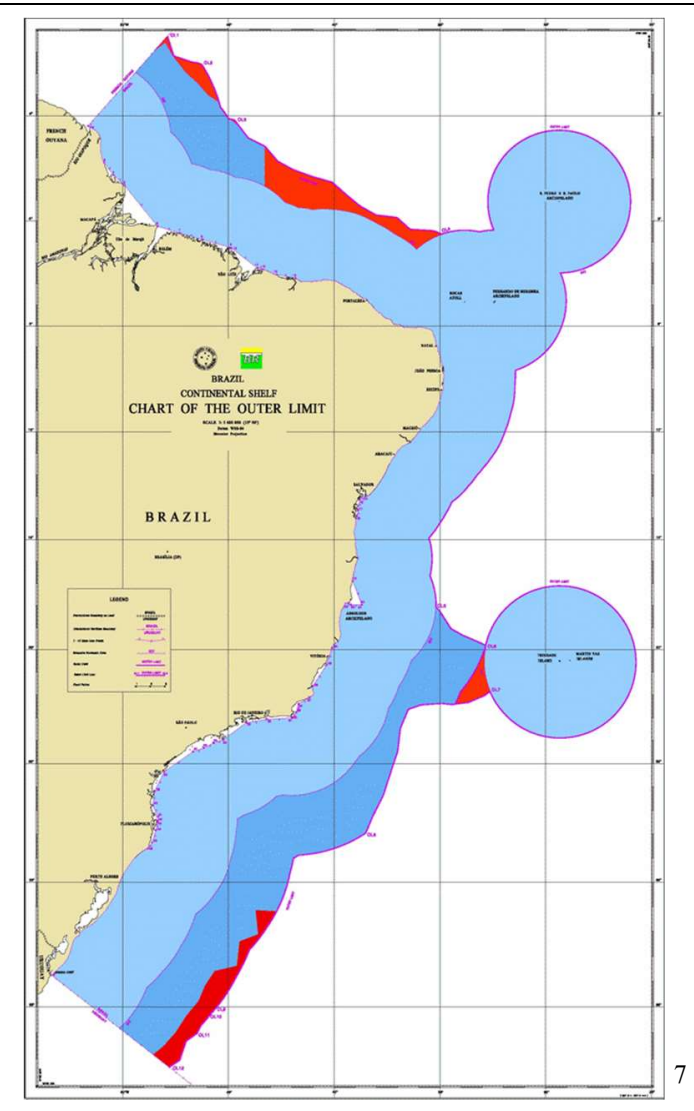

Em razão de o Estado brasileiro ter optado por submeter apartadamente à CLPC uma proposta revista parcial para cada uma das três regiões, em abril de 2015 foi encaminhada a primeira delas, a proposta revista parcial da Região $\mathrm{Sul},{ }^{8}$ que pretende incorporar à plataforma continental brasileira uma área de 50 mil km².

Recentemente, em setembro de 2017, o Brasil submeteu à CLPC a proposta revista parcial relativa à Região Equatorial, que visa adicionar $130 \mathrm{mil} \mathrm{km}^{2}$ de área à plataforma continental sob jurisdição brasileira.

Enfim, está sob elaboração a última proposta revista parcial a ser apresentada pelo Brasil, a da Região Oriental, que agrega 20 mil $\mathrm{km}^{2}$ à área da plataforma continental nacional e totaliza os 200 mil km² não atendidos pelas recomendações da CLPC de 2007. Posto isto, de acordo com a Marinha do Brasil (BRASIL, 2018)

[...] a definição do limite exterior da plataforma continental será um legado de fundamental importância para o futuro das próximas gerações de brasileiros, que verão aumentadas as possibilidades de descoberta de novos campos petrolíferos, a exploração de recursos da biodiversidade marinha, que a ciência atual reconhece como um dos campos mais promissores do desenvolvimento da biogenética, e de 
exploração de recursos minerais em grandes profundidades, ainda não viáveis economicamente.

A posição pioneira assumida pelo Brasil até o momento rendeu ao país uma vasta experiência, que passou a ter capacitação técnica e destaque no cenário internacional, podendo passar a assessorar outros Estados costeiros no estabelecimento do limite exterior de suas plataformas continentais.

\section{EXPLORAÇÃO DA PLATAFORMA CONTINENTAL ESTENDIDA: OPORTUNIDADES E DESAFIOS.}

Bem como elucidado até o momento, ainda são indetermináveis os recursos disponíveis no mar, até porque, constantemente são realizadas novas pesquisas que visam explorar as desconhecidas profundezas marinhas. Somente na história recente, com o desenvolvimento de novas tecnologias, o homem conseguiu acessar os recursos da plataforma continental, e não há dúvida de que os seus impactos econômicos foram impressionantes. Conforme ilustra Eliane M. Octaviano Martins (2013, p. 2)

Desde o século XX, a evolução tecnológica desvela outras perspectivas da exploração do leito e subsolo marítimos, revelando às nações que o mar consigna relevante fonte de riquezas e de fundamental importância estratégica como supridor de matéria-prima, consagrando ainda mais o espaço marítimo como um dos baluartes da economia internacional globalizada.

Nesse sentido, em pleno o século XXI, momento em que cada vez mais são escassos os recursos presentes nos continentes, a continuidade do acelerado ritmo de crescimento das economias globais depende veementemente da exploração dos recursos depositados no leito e subsolo oceânicos. Portanto, ao regular os espaços marítimos, mais especificamente a plataforma continental, a CNUDM implica na condição que terão os players de explorar os recursos presentes nas profundezas oceânicas.

Em âmbito nacional, a exploração dos recursos naturais da plataforma continental possui como fundamento o artigo 20, V e IX da Constituição Federal

Art. 20. São bens da União:

$[\ldots]$

V - os recursos naturais da plataforma continental e da zona econômica exclusiva;

$[\ldots]$

IX - os recursos minerais, inclusive os do subsolo; 
A exploração deve obervar o princípio constitucional que garante o direito ao meio ambiente equilibrado, presente no artigo $225, \S 1^{\circ}$, IV e $\S 2^{\circ}$ da Constituição. ${ }^{9}$

Além disso, conforme preceitua o artigo 48, V da Carta Magna, cabe ao Congresso Nacional, com a sanção do Presidente da República, dispor sobre os limites do território nacional, espaço aéreo e marítimo e bens do domínio da União.

Desta forma, a Lei Federal no 8.617, de 4 de janeiro de 1993, define em seu artigo 12 que o Brasil exerce direitos de soberania sobre a plataforma continental, para efeitos de exploração dos recursos naturais. ${ }^{10}$ Consequentemente, levando em conta a ampla costa brasileira que possui mais de 7 mil km de extensão, a possibilidade de prolongamento da plataforma continental além das 200 milhas marítimas contemplada pela CNUDM representa uma oportunidade de grande peso econômico para a sociedade e futuras gerações. Riquezas como petróleo e gás natural já são uma realidade nesse ambiente, portanto, ampliar a plataforma continental significa ampliar as possibilidades de serem descobertos novos campos para extração desses recursos.

Cabe à Agência Nacional de Petróleo, Gás Natural e Biocombustíveis (ANP) a administração dos direitos de exploração desses recursos, conforme prescreve o artigo 21 da Lei Federal nº 9.478, de agosto de 1997 (Lei do Petróleo). Todavia, é cediço que nenhum dos regimes legais aplicáveis à exploração e produção do petróleo - concessão, partilha de produção e cessão onerosa - foram concebidos levando em conta todas as particularidades de quando a atividade se desenvolve na plataforma continental, exceto para efeitos de cálculo e distribuição de royalties.

Por sua vez, no que toca à exploração de recursos minerais sólidos na plataforma continental, é aplicado o Código de Mineração devido à ausência de legislação específica. É que após diversas alterações, o termo "plataforma submarina" foi suprimido do inciso IV do artigo 22 do referido Código. ${ }^{11}$

Renata Baptista Zanin (2014, p. 450) explica que

[...] o Código de Minas deverá ser aplicado para atividades na plataforma continental, entendimento que coaduna com a interpretação integrativa dos artigos 20, V e IX, 48, I, e 176 da Constituição Federal, que formam uma consistente base legal para autorização e concessão para pesquisa e lavra de minérios no solo e subsolo da plataforma continental, embora não expressa. 
A viabilidade econômica para a explotação de recursos minerais sólidos na plataforma estentida não está distante da realidade brasileira. Da mesma forma, pesquisas indicam a possibilidade de as reservas do pré-sal se prolongarem até a plataforma continental além das 200 milhas marítimas (TRINDADE, 2015, p. 163).

No entanto, quando explorada a plataforma estentida, o Estado costeiro que sobre ela detém direitos de soberania estará usufruindo de recursos que pertenceriam à todos os povos. Isso decorre do fato de que, antes desse espaço ser convertertido em plataforma estendida, ele pertence à Área, patrimônio comum da humanidade (res communis).

Sob este ângulo, o Estado brasileiro deve estar preparado para regulamentar em seu direito doméstico, no que lhe compete, como ocorrerão os pagamentos e contribuições relativos ao aproveitamento da plataforma continental além das 200 milhas marítimas à AIFM, conforme exige o artigo 82 da Convenção.

Traçando um paralelo entre o royalty que usualmente se cobra da exploração petrolífera no Brasil, Karoline Lins Câmara Marinho de Souza (2015, p. 345) define que

[...] a exploração dos recursos da plataforma continental estendida pelo Estado costeiro exige o pagamento de uma obrigação com natureza de royalty à Autoridade dos Fundos Marinhos, levando em conta que este espaço, conforme já se disse alhures, caso não fosse demarcado como plataforma estendida, seria pertencente à Área, que, por sua vez, submete-se ao regime de patrimônio comum da humanidade.

Outrossim, o estabelecimento de um royalty é mais adequado para a Autoridade Marinha, enquanto órgão internacional, porque o tributo está relacionado ao exercício da soberania nacional para estabelecimento de obrigações pecuniárias oriundas do patrimônio dos contribuintes, enquanto que o "pagamento" ou a "contribuição" não denota a ideia de prerrogativa soberana, mas simplesmente transmite o sentido de uma obrigação internacional criada pelo uso de região originalmente de propriedade de toda a humanidade.

Apesar de delimitada a natureza jurídica - royalty — da contribuição expressa no artigo 82 da CNUDM, ainda restam indefinidas questões atinentes: (i) ao prazo para cobrança e pagamento; (ii) ao valor do royalty a ser pago (em dinheiro ou em espécie?); (iii) à possível isenção da cobrança para o Brasil. ${ }^{12}$

Nesse diapasão, Christiano Sávio Barros Figuerôa assevera que (2014, p. 127) 


\begin{abstract}
A UNCLOS não determinou a quem cabe precisar o montante do pagamento ou a contribuição em espécie; a ISBA carece de competências para regulamentar tais aspectos. $\mathrm{O}$ artigo 82, diante disso, requererá cooperação internacional e boa-fé e em sua implementação, que ainda encerra mais dúvidas que respostas. À medida que os Estados costeiros concluam a delineação definitiva e obrigatória dos limites exteriores de suas plataformas continentais com base nas recomendações da Comissão de Limites, seu relacionamento com a Autoridade a respeito do pagamento de royalties sobre o aproveitamento da plataforma continental estendida tenderá a exigir maior atenção internacional.
\end{abstract}

Dessa forma, levando em conta que a tendência nos próximos anos é intensificar-se a captação de recursos na plataforma continental, e iniciar-se a exploração da plataforma estendida, o Brasil estará diante de grandes oportunidades e desafios, os quais serão fundamentais para o desenvolvimento econômico da nação como um todo.

\title{
3.1 A (IM)POSSIBILIDADE DE EXPLORAÇÃO DA PLATAFORMA CONTINENTAL ESTENDIDA PREVIAMENTE ÀS NOVAS RECOMENDAÇÕES DA CLPC
}

Após as recomendações da CLPC de 2007, o Governo brasileiro formalizou pedidos de esclarecimentos sobre diversos aspectos jurídicos, técnicos e formais das recomendações que geravam dúvidas para o país. No entanto, o conteúdo desses pedidos e a resposta da Comissão permanecem sigilosos. O que se sabe, é que não foram suficientes para que se alcançasse uma convergência de posições com o Brasil, visto que manteve sua decisão de enviar propostas revistas parciais à CLPC (FIGUERÔA, p. 230-231).

É que a CNUDM prevê em seu artigo 76, $\S 8^{\circ}$, que os limites da plataforma continental estabelecidos pelo Estado costeiro com base nas recomendações da CLPC serão definitivos e obrigatórios. Nesse contexto, paira a dúvida se o Brasil poderia exercer seus direitos de soberania sobre a plataforma continental estendida enquanto aguarda as novas recomendações da Comissão da ONU à respeito das áreas não atendidas pelo pleito de 2004.

Após o Governo brasileiro tomar ciência de que estavam sendo realizados e publicados trabalhos científicos por pesquisadores, em sua maioria russos e chineses, sobre a plataforma continenal estendida sem a devida autorização da Marinha, a CIRM (BRASIL, 2010) adotou em 2010 a Resolução $n^{\circ} 3$, de 26 de agosto de 2010, por meio da qual declarou que 
[...] independentemente de o limite exterior da Plataforma Continental (PC) além das 200 milhas náuticas não ter sido definitivamente estabelecido, o Brasil tem o direito de avaliar previamente os pedidos de autorização para a realização de pesquisa na sua PC além das $200 \mathrm{MN}$, tendo como base a proposta de limite exterior encaminhada a Comissão de Limites da Plataforma Continental (CLPC), em 2004, e publicada na página eletrônica da ONU.

Apesar de não mencionar que o Brasil teria o direito de explorar econômicamente a plataforma continental além das 200 milhas, a Resolução foi objeto de críticas por alguns veículos de comunicação em âmbito nacional e internacional, tendo em vista uma possível interpretação da medida como "ato unilateral" do Governo brasileiro visando proteger as reservas do pré-sal.

Por sua vez, Christiano Sávio Barros Figuerôa (2014, p. 234) explica que

Tais análises se equivocam ao considerarem que o direito do Brasil à sua plataforma continental estendida só existiria a partir de uma decisão final da CLPC e do estabelecimento dos limites exteriores com base nas recomendações da Comissão. O direito do Estado costeiro a sua plataforma continental é inerente, decorre do fato do prolongamento natural de sua massa terrestre sob o mar e independe de qualquer declaração expressa, seja da Comissão, seja do próprio Estado costeiro. A Resolução CIRM no 3/2010 expressamente destaca, nesse sentido, o artigo 77 da UNCLOS. O procedimento na Comissão possibilita que os limites exteriores da plataforma continental se tornem definitivos e obrigatórios diante de terceiros Estados, mas não implica que o Brasil ou qualquer Estado costeiro só depois disso possa exercer seus direitos soberanos. A decisão do Brasil tampouco constituiu estabelecimento unilateral dos limites exteriores de sua plataforma. Além de a resolução da CIRM mencionar que os limites não eram definitivos e que se preparava outra proposta para a Comissão, o país não efetuou qualquer depósito de cartas náuticas, linhas e coordenadas de limites junto ao SGNU.

Na mesma direção, Maria Augusta Paim (apud, ALBUQUERQUE, 2014, p. 335-337) aponta que

Apesar de ainda não ter adotado de forma definitiva os limites exteriores de sua plataforma continental, o Brasil já poderia exercer jurisdição sobre a área de sua plataforma continental pretendida, pelo fato de que os seus direitos de soberania sobre a área não dependem de declaração expressa, além dos motivos a seguir, ressaltados pelo Comandante Alexandre Tagore Medeiros de Albuquerque:

[...] no rigor da interpretação das disposições da CNUDM, o Brasil ainda não adotou, definitivamente, os limites exteriores da sua plataforma continental. Contudo, entendemos que isso não quer dizer, necessariamente, que o Brasil não possa exercer qualquer tipo de jurisdição sobre a sua área de plataforma continental pretendida. Sob nossa ótica, o Brasil, ao contrário dos demais Estados costeiros que ainda nem sequer prontificaram suas propostas de limite exterior da plataforma continental, poderá não apenas proibir que qualquer outro Estado explore e aproveite recursos naturais da nossa plataforma continental pretendida, mas também poderá, ele próprio, explorar e aproveitar os recursos naturais dessa mesma plataforma continental. Em apoio a essa opinião, podem ser listados, entre outros, os seguintes pontos: 
a) A CNUDM, que define o conceito de plataforma continental, está em vigor para o Brasil.

b) A Lei $\mathrm{n}^{\circ} 8.617 / 93$ determina que o limite exterior da plataforma continental deve ser estabelecido de conformidade com as disposições do artigo 76 da CNUDM e informa que o Brasil exerce direitos de jurisdição quanto à exploração e ao aproveitamento dos recursos naturais da plataforma continental.

c) A DOALOS [Divisão de Assuntos Oceânicos e do Direito do Mar] das Nações Unidas registra no seu sítio de rede que o Brasil adota uma plataforma continental até 200 milhas ou até o bordo exterior da margem continental.

d) a CIA [Central Inteligence Agency], no seu sítio de rede relativo ao World Factbook, também registra, por sua vez, que o Brasil adota uma plataforma continental até 200 milhas ou até o bordo exterior da margem continental.

e) o Sumário Executivo referente à proposta brasileira, o qual contém informações precisas sobre as coordenadas geográficas do limite exterior proposto para a nossa plataforma continental, está disponível no sítio de rede da DOALOS desde 2004. Até o momento, exceto a nota verbal formulada pelos Estados Unidos da América, a qual foi rechaçada pela CLPC, nenhum outro Estado encaminhou qualquer nota verbal ou formulou um protesto formal em relação à nossa proposta. Tal situação nos permite inferir que os Estados, ainda que nosso País não tenha estabelecido e adotado os limites exteriores da sua plataforma continental, reconhecem o direito exclusivo do Brasil no que tange ao exercício de jurisdição quanto à exploração e ao aproveitamento dos recursos naturais dos fundos marinhos da área de plataforma continental pretendida e já submetida à CLPC.

Uma vez que o Brasil concorde com a extensão da plataforma continental brasileira recomendada pela CLPC, deverá formular documento nacional interno com o reconhecimento do limite exterior da plataforma continental brasileira e depositar seus mapas e listas de coordenadas geográficas definitivos junto ao Secretário-Geral da ONU para a publicidade internacional.

Logo, embora o pleito brasileiro não tenha sido integralmente validado pela Comissão da ONU, uma parcela da doutrina sustenta que o Estado não deve esperar até que haja o estabelecimento dos limites exteriores definitivos e obrigatórios de sua plataforma continental estendida com base nas recomendações da CLPC para exercer seus direitos soberanos de exploração e aproveitamento econômico dos recursos ali existentes (FIGUERÔA, 2014, p. 266).

No entanto, a ANP afirmou que a plataforma continental estendida não está sendo explorada. Ademais, o Estado-Maior da Armada e o Departamento Nacional de Produção Mineral (DNPM) confirmaram que não será explorada a plataforma estendida enquanto as propostas revistas brasileiras não forem examinadas pela CLPC, o que demonstra o respeito do Brasil às recomendações da Comissão e ao procedimento criado pela CNUDM (MONEBHURRUN, 2015, p. 55).

Por conseguinte, na visão de Nitish Monebhurrun (2015, p. 55) “[...] a Resolução 03/10 permitiu apenas as avaliações de pedidos para a exploração futura da plataforma estendida" (MONEBHURRUN, 2015, p. 55). Portanto, não se trata de um ato unilateral do Estado brasileiro, 
visto que, além de não possuir atributos para tanto, traduz-se unicamente numa forma de racionalizar o trabalho administrativo.

Ultrapassados mais de dez anos desde às recomendações da CLPC de 2007, o que se depreende desse período é que o Brasil mantém uma absoluta observância ao direito processual previsto pela CNUDM. O contrário seria imaginar um Estado além do Direito Internacional, com uma relativização de suas obrigações.

\section{CONSIDERAÇÕES FINAIS}

Após os mais de 30 anos de existência da CNUDM, a mesma provou ser uma verdadeira “Constituição dos Mares": Normatizou o maior bem natural à disposição do homem que há milênios era pautado pelo direito consuetudinário.

Especialmente em relação aos espaços marítimos, não resta dúvida de que ao delimitá-los juridicamente, a Convenção impediu que diversas querelas em âmbito internacional viessem a se concretizar. No entanto, é cediço que o árduo processo de delimitação desses espaços entre os Estados ao redor do globo terrestre ainda perdurará por algumas décadas.

No que tange ao regime jurídico da plataforma continental, a Convenção inovou substancialmente ao prever a possibilidade de os Estados costeiros estenderem suas plataformas continentais para além das 200 milhas marítimas a partir das linhas de base do mar territorial. Para o Brasil isso significa uma oportunidade ainda incalculável em termos econômicos.

Além disso, o país merece destaque em âmbito internacional por ter sido um dos pioneiros na tarefa de desbravar o mar e seus fundos oceânicos para a realização de pesquisas atinentes ao procedimento de extensão da plataforma continental. Apesar de já ter o reconhecimento de grande parte de sua plataforma estendida, esse é somente o princípio dos demais desafios que estão por vir.

Primeiramente, o Brasil ainda depende da chancela da CLPC para explorar os recursos dos $200 \mathrm{~km}^{2}$ de área que não foram atendidos pelas recomendações de 2007. Além disso, a exploração da plataforma continental além das 200 milhas marítimas requer sejam cumpridas uma série de 
determinações impostas pela CNUDM, entre elas, os pagamentos e contribuições à AIFM que são previstos no artigo 82 da Convenção.

Vimos também que ainda pairam certas indefinições acerca de como se efetuarão as explorações e contribuições no que diz respeito à plataforma continental estendida. De igual modo, os direitos de soberania sobre toda essa extensa área subjacente ao mar gera ao país o ônus de mantê-la sob constante fiscalização, visto ser responsável por manter esse espaço salvaguradado de desastres ambientais e explorações não autorizadas.

Dessa forma, o Brasil deverá buscar respostas e soluções para enfrentar todas essas temáticas em breve. Espera-se que o povo, verdadeiro detentor da soberania sobre os leitos e subsolos oceânicos, possa ser o maior herdeiro dessa imensa riqueza após todos os pretéritos e futuros anos de comprometimento com virtuosa causa.

\section{NOTAS}

1. "Sua descoberta se deu por volta de 1930, a partir de quando muitos Estados detectaram a existência de petróleo e gás sob o solo e subsolo de suas terras submersas para além do mar territorial” (MAZZUOLI, 2012, p. 796).

2. "[...] o limite exterior da plataforma continental, nos trechos em que a margem continental ultrapassa as duzentas milhas, poderá estender-se até a linha de $1 \%$ de espessura de sedimentos ou até a uma distância de sessenta milhas do pé do talude, desde que essas linhas não ultrapassem a distância de 350 milhas das linhas de base ou cem milhas da isóbata de 2.500 metros" (MACHADO, 2015, p. 64).

3. Luiz Alberto Figueiredo Machado (2015, p. 64) precisa ao dizer que "[...] o trabalho de fixação do limite exterior da plataforma continental passa a ser um exercício, pelo Estado costeiro, de aplicação dessas diferentes variáveis, com o propósito de encontrar a combinação mais favorável à ampliação de sua área de jurisdição".

4. O mapa demonstra o limite exterior da plataforma continental brasileira. Em azul a plataforma continental até as 200 milhas marítimas e em verde a pretensão de plataforma continental além das 200 milhas marítimas (ONU, 2013). 
5. Os EUA afirmaram que os dados coletados pelo Brasil à respeito da espessura dos sedimentos da plataforma continental não convergiam, em diversos trechos, com os dados retirados de fontes publicamente disponíveis. Em relação a Cadeia Vitória-Trindade, a carta norte-americana alegou que referida região não é parte da margem continental brasileira além das 200 milhas marítimas.

6. Os $200 \mathrm{mil} \mathrm{km²}$ de área não atendidos pela CLPC estão distribuídos em zonas do Cone do Amazonas, Cadeias Norte Brasileira e Vitória-Trindade e Margem Continental Sul

7. O mapa aponta em vermelho as áreas que não foram atendidas pelas recomendações da CLPC (MENEZES, 2015, p. 146).

8. $\mathrm{Na} 47^{\mathrm{a}}$ Reunião dos Estados-Partes da CNUDM, realizada entre 16 de julho à 31 de agosto de 2018, foi deliberado que a subcomissão responsável pelas propostas revistas do Brasil irá emitir suas recomendações sobre a proposta revista parcial da Região Sul durante a $48^{\mathrm{a}}$ Reunião, que acontecerá nos meses de outubro e novembro de 2018.

9. A exploração sustentável da plataforma continental é elementar, visto que "[...] conforme a evolução e surgimento de novas técnicas, entendemos que, pela exploração dos recursos minerais e energéticos dos fundos dos oceanos, solo e subsolo, deram início a um processo de destruição do meio ambiente marinho e que se aprofundou com o descobrimento de novas técnicas de exploração e transporte nas áreas marinhas e espaços marítimos" (AUTOR, 2019, no prelo).

10. A Lei Federal $n^{\circ} 8.617$, de 4 de janeiro de 1993, contudo, não faz qualquer menção à termos como "plataforma continental estendida" ou "plataforma continental além das 200 milhas marítimas". Somente determina que o limite exterior da plataforma continental será fixado de conformidade com os critérios estabelecidos no art. 76 da CNUDM.

11. O termo "plataforma submarina" somente foi preservado no artigo 25, IV do Decreto $\mathrm{n}^{\circ}$ 62.934, de 2 de julho de 1968 - Regulamento do Código de Mineração.

12. Maria Augusta Paim alude que "no caso do Brasil, é pouco provável que consiga obter a isenção dos referidos pagamentos ou contribuições no que se refere à exploração de petróleo em tal área, sobretudo porque alcançou a autossuficiência em petróleo em 2006 e já não é mais considerado um 
país em desenvolvimento, mas, sim, emergente, pela Organização para a Cooperação e Desenvolvimento Econômico (OCDE)” (PAIM, 2014, p. 343).

\section{THE EXTENSION OF THE BRAZILIAN CONTINENTAL SHELF BEYOND 200 NAUTICAL MILES: OPPORTUNITIES AND CHALLENGES}

This study has the objective of investigating, based on the United Nations Convention on the Law of the Sea - UNCLOS, the legal regime of the Continental Shelf and the possibility of extension of its outer limit beyond the two hundred nautical miles limit — as stated in the UNCLOS's article 76 - and to cover the operation of the Commission on the Limits of the Continental Shelf, as well as providing answers regarding its economic impacts in oil, natural gas and other mineral resources exploitation in the seabed and subsoil that compose the Blue Amazon, under the sovereignty of the Brazilian State. Likewise, from the standpoint of the Brazilian case, difficulties are foreseen when the application of the UNCLOS's article 82 is subjected to the proof of the facts, what highlights the conception that the exploitation of the extended continental shelf will generate a series of opportunities and challenges for the country.

Keywords: Article 76. Blue Amazon. Continental Shelf Expansion. Commission on the Limits of the Continental Shelf. United Nations Convention on the Law of the Sea.

\section{REFERÊNCIAS}

BRASIL. Constituição da República Federativa do Brasil. São Paulo: Saraiva, 2018.

. Comando da Marinha. Secretaria da Comissão Interministerial para os Recursos do Mar. Amazônia Azul. Disponível em: <https://www.mar.mil.br/secirm/portugues/amazoniaazul.html>. Acesso em: 18 out. 2017.

. Comando da Marinha. Secretaria da Comissão Interministerial para os Recursos do Mar. Plano de levantamento da plataforma continental brasileira. Disponível em: $<$ https://www.marinha.mil.br/secirm/leplac\#lei>. Acesso em: 17 jan. 2018. 
. Comando da Marinha. Comissão Interministerial para os Recursos do Mar. Resolução ${ }^{0}$ 3, de 26 de agosto de 2010. Diário Oficial da União, Brasília, DF, nº 170, 3 set. 2010. Seção 1, p. 28. Disponível em: $<$ https://www.marinha.mil.br/secirm/sites/www.marinha.mil.br.secirm/files/resolucao-32010.pdf>. Acesso em: 4 nov. 2018.

. Decreto $\mathrm{n}^{\mathrm{o}}, 28.840$, de 8 de novembro de 1950. Diário Oficial da União, Poder Executivo, Rio de Janeiro, RJ, 8 nov. 1950. Seção 1, p. 16616. Disponível em: $<$ http://www2.camara.leg.br/legin/fed/decret/1950-1959/decreto-28840-8-novembro-1950329258-publicacaooriginal-1-pe.html>. Acesso em: 27 ago. 2018.

. Decreto $\mathrm{n}^{\mathrm{o}}, 62.934$, de 2 de julho de 1968. Diário Oficial da União, Poder Executivo, Brasília, DF, 5 jul. 1968. Seção 1, p. 5593. Disponível em: $<$ http://www2.camara.leg.br/legin/fed/decret/1960-1969/decreto-62934-2-julho-1968-404797publicacaooriginal-1-pe.html>. Acesso em: 4 nov. 2018,

. Decreto $n^{\circ}, 98.145$, de 15 de setembro de 1989. Diário Oficial da União, Poder Executivo, Brasília, DF, 18 nov. 1989. Seção 1, p. 16483. Disponível em: $<$ https://www.planalto.gov.br/ccivil_03/decreto/1980-1989/d98145.htm>. Acesso em: 17 jan. 2018.

. Lei no ${ }^{\circ}$ 8.617, de 4 de janeiro de 1993. Diário Oficial da União, Poder Executivo, Brasília, DF, 5 abr. 1993. Seção 1, p. 57. Disponível em: $<$ https://www.planalto.gov.br/ccivil_03/leis/18617.htm>. Acesso em: 17 jan. 2018.

. Lei no, 9.478 , de 6 de agosto de 1997. Diário Oficial da União, Poder Legislativo, Brasília, $\overline{\mathrm{DF}} 7$ ago. 1997. Seção 1, p. 16925. Disponível em: $<$ http://www.planalto.gov.br/ccivil_03/LEIS/L9478.htm>. Acesso em: 11 set. 2018.

DE SOUZA, Karoline Lins Câmara Marinho. Critérios para cobrança de contribuição internacional pela utilização da plataforma continental estendida: panorama geral e impactos financeiros de sua aplicação quanto à exploração de petróleo na camada pré-sal no Brasil. Cadernos do programa de pós-graduação em direito da UFRGS, Porto Alegre, n. 1, v. 10, p. 333-370, 2015.

FIGUERÔA, Christiano Sávio Barros. Limites exteriores da plataforma continental do Brasil conforme o direito do mar. Brasília: Funag, 2014.

GIBERTONI, Carla Adriana Comitre. Teoria e prática do direito marítimo. Rio de Janeiro: Renovar, 2014.

GOUVEIA, Jorge Barcelar. O direito internacional dos espaços. Cadernos da escola de direito, Paraná, n. 4, v. 1, p. 131-183, 2004. 
GUEDES, Armando M. Marques. Direito do mar. Coimbra: Coimbra Editora, 1998.

GUERRA, Sidney. Curso de direito internacional público. 8. ed. São Paulo: Saraiva, 2015.

MACHADO, Luiz Alberto Figueiredo. A plataforma continental brasileira e o direito do mar: considerações para uma ação política. Brasília: Funag, 2015.

MARTINS, Eliane M. Octaviano. Curso de direito marítimo. 4. ed. Barueri: Manole, 2013. v. 1.

MAZZUOLI, Valerio de Oliveira. Curso de direito internacional público. 6. ed. rev. São Paulo: RT, 2012.

MENEZES, Wagner. O direito do mar. Brasília: Funag, 2015.

MONEBHURRUN, Nitish. Da inexistência de um ato unilateral do Brasil sobre o direito de realizar pesquisas na sua plataforma continental além das 200 milhas: comentário sobre a resolução 03/30 da CIRM. In: DE OLIVEIRA, Carina Costa (Org.). Meio ambiente marinho e direito: exploração e investigação na zona costeira, na plataforma continental e nos fundos marinhos. Curitiba: Joruá, 2015.

AUTOR. 2019 (no prelo).

PAIM, Maria Augusta. A expansão da amazônia azul: a plataforma continental do Brasil além das 200 milhas náuticas. In: BEIRÃO, André Panno. PEREIRA, Antônio Celso Alves (Org.). Reflexões sobre a convenção do direito do mar. Brasília: Funag, 2014.

RIBEIRO, Manuel de Almeida. O artigo 82..$^{\circ}$ da convenção de montego bay: aspectos práticos e conceptuais. In: RIBEIRO, Marta Chantal (Coord.). 20 anos da entrada em vigor da CNUDM: Portugal e os recentes desenvolvimentos no direito do mar. Porto: CIIMAR - FDUP, p. 109-114, 2015.

TRINDADE, Adriano Drumond Cançado. A exploração de petróleo e demais recursos minerais da plataforma continental: regimes jurídicos aplicáveis. In: DE OLIVEIRA, Carina Costa (Org.). Meio ambiente marinho e direito: exploração e investigação na zona costeira, na plataforma continental e nos fundos marinhos. Curitiba: Joruá, 2015.

UNITED NATIONS. Comission on the limits of the continental shelf. Executive summary of the submission by $2013 . \quad$ Brazil. Disponível 
$<$ http://www.un.org/depts/los/clcs_new/submissions_files/bra04/bra_exec_sum.pdf $>$. Acesso em: 15 jul. 2018.

ZANELLA, Tiago Vinicius. Curso de direito do mar. Curitiba: Juruá, 2013.

ZANIN, Renata Baptista. MORE, Rodrigo Fernandes. A expansão da amazônia azul: a plataforma continental do Brasil além das 200 milhas náuticas. In: BEIRÃO, André Panno. PEREIRA, Antônio Celso Alves (Org.). Reflexões sobre a convenção do direito do mar. Brasília: Funag, 2014.

Trabalho enviado em 06 de novembro de 2019 Aceito em 06 de fevereiro de 2020 